Check for updates

Cite this: RSC Adv., 2019, 9, 6310

\title{
Structural basis for the formation of soy protein nanofibrils $\dagger$
}

\author{
Leila Josefsson, Melker Cronhamn, Malin Ekman, Hugo Widehammar, Åsa Emmer \\ and Christofer Lendel (iD *
}

Amyloid-like protein nanofibrils (PNFs) can assemble from a range of different proteins including diseaseassociated proteins, functional amyloid proteins and several proteins for which the PNFs are neither related to disease nor function. We here examined the core building blocks of PNFs formed by soy proteins. Fibril formation at $\mathrm{pH} 2$ and $90{ }^{\circ} \mathrm{C}$ is coupled to peptide hydrolysis which allows isolation of the PNF-forming peptides and identification of them by mass spectrometry. We found five peptides that constitute the main building blocks in soy PNFs, three of them from the protein $\beta$-conglycinin and two from the protein glycinin. The abilities of these peptides to form PNFs were addressed by amyloid prediction software and by PNF formation of the corresponding synthetic peptides. Analysis of the structural context in the native soy proteins revealed two structural motifs for the PNF-forming peptides: (i) socalled $\beta$-arches and (ii) helical segments involved in quaternary structure contacts. However, the results suggest that neither the native structural motifs nor the protein of origin defines the morphology of the PNFs formed from soy protein isolate.

Received 28th December 2018 Accepted 15th February 2019

DOI: 10.1039/c8ra10610j

rsc.li/rsc-advances amyloid-like PNFs. ${ }^{11,19}$ The two proteins have a high degree of structural and sequential homology but differ in the quaternary structure. $\beta$-Conglycinin is a trimer consisting of three different chains $\left(\alpha, \alpha^{\prime}\right.$ and $\left.\beta\right)$, while glycinin is a hexamer built from five different subunits (G1-G5). ${ }^{20,21}$ The three-dimensional structure of the subunits with two jelly-roll $\beta$-barrels and extended $\alpha$ helical domains is also similar to the architecture of other seed storage proteins (e.g. ref. 22-26). Each glycinin subunit is posttranslationally cleaved into an acidic chain and a basic chain that are connected through a disulfide bond. ${ }^{27}$ Previous studies have reported that all three chains of $\beta$-conglycinin can form fibrils and that the differences in fibrillation rates might be due to differences in hydrolysis. ${ }^{28}$ Tang and Wang found that $\beta$ conglycinin forms PNFs more easily than glycinin. ${ }^{19}$ However, Dong et al. reported that when the acidic and the basic chains of glycinin were separated, the acidic subunit easily formed fibrils, while the basic subunits appeared to inhibit this process. ${ }^{29}$

Several studies have found that proteins undergo the transition into amyloid-like PNFs when incubated at low pH (typically around 2) and high temperature $\left(70-90{ }^{\circ} \mathrm{C}\right) \cdot{ }^{11,13,16,19,30-32}$ The fact that globular proteins are denatured likely contributes to the fibrillation-promoting effect at these conditions but it has also became evident that acid-induced hydrolysis of the peptide backbone can play a crucial role..$^{\mathbf{8 , 1 3 , 1 9 , 3 3 , 3 4}}$ The role of hydrolysis can be understood in the light of that the core structures of PNFs only consist of parts of the full-length protein. Hence, large parts of the protein chain are not critical for forming the amyloid structure; rather it will in many cases lead to structural frustrations and reduce the thermodynamic stability of the PNF
Department of Chemistr

$\dagger$ Electronic supplementary information (ESI) available: Additional tables and figures. See DOI: 10.1039/c8ra10610j 
state $^{35}$ Therefore, the shorter peptides originating from hydrolysis will in general have more favourable free energy for the assembly into PNFs than the full-length polypeptides. A recent study from our lab also suggests that the PNF morphology, and thereby also the nanomechanical properties, can be determined by the hydrolysis process. ${ }^{8}$ In the present study we explored the PNF-forming peptide segments in soy proteins with the aim to better understand how SPI, and potentially other plant proteins, can be used for production of PNFs with defined morphology for nanomaterial applications.

\section{Materials and methods}

\section{Materials}

Guanidine hydrochloride (GuHCl, product number G4505), trifluoroacetic acid (TFA, product number T6508), acetonitrile (ACN, product number 34881-M), thioflavin $\mathrm{T}$ (ThT, product number T3516) and hydrochloric acid ( $\mathrm{HCl}$, product number 30721) were purchased from Sigma Aldrich (product numbers in parenthesis). The matrices for matrix-assisted laser desorption/ionization time of flight (MALDI-TOF) mass spectrometry (MS), i.e. 2,5-dihydroxybensoic acid (DHB, product number 8201346) and $\alpha$-cyano-4-hydroxycinnamic acid (HCCA, product number 8201344 ), and the peptide calibration standard (covering mass range: 1000-3200 Da, product number 8206195), were products from Bruker Daltonik. 1,4-Dithiothreitol (DTT, product number 443852A) was purchased from VWR and tris(hydroxymethyl)aminomethane (Tris, product number 37190) was from Serva feinbiochemica. All water was purified with Millipore synergy 185 to $18.2 \mathrm{M} \Omega \mathrm{cm}$ at $25{ }^{\circ} \mathrm{C}$. The SPI, SUPRO 120 IP, was kindly provided by Solae Belgium N.V.

\section{Preparation of PNFs}

SPI powder corresponding to a final concentration of $50 \mathrm{mg} \mathrm{ml}^{-1}$ was dispersed in $0.1 \mathrm{M} \mathrm{HCl}$ and stirred in a glass beaker for $1 \mathrm{~h}$ at room temperature. The dispersion was then dialyzed against $0.01 \mathrm{M} \mathrm{HCl}(\mathrm{pH} 2)$ using a membrane from Spectrum laboratories with 6-8 kDa molecular weight cut-off for 24 hours at room temperature. The dialysis solution was changed 2 times. The insoluble material was separated by centrifugation at $12000 \times g(30 \mathrm{~min})$ in $50 \mathrm{ml}$ plastic tubes followed by filtration of the supernatant through a filter with $0.45 \mu \mathrm{m}$ pore size from VWR. The final protein concentration was $14 \mathrm{mg} \mathrm{ml}^{-1}$, as estimated by dry weight measurements. PNF formation was achieved by incubation of the solution at $90{ }^{\circ} \mathrm{C}$ at quiescent conditions. The presence of PNFs was confirmed using ThT fluorescence and atomic force microscopy (AFM). Samples for ThT fluorescence measurements were prepared by mixing $0.2 \mathrm{ml}$ protein solution with $2.4 \mathrm{ml} 50 \mu \mathrm{M}$ ThT solution. Fluorescence was measured on a Varian Cary Eclipse Spectrofluorometer with excitation at $440 \mathrm{~nm}$ and emission spectra recorded between 460 and $600 \mathrm{~nm}$. PNFs for circular dichroism (CD) and MS analysis were extensively purified by repeated concentration of the sample in a spin filter with $100 \mathrm{kDa}$ molecular weight cut-off membrane (GE Healthcare) spun at $1500 \times g$ followed by dilution to the initial volume.

\section{Gel electrophoresis}

Samples for sodium dodecyl sulfate polyacrylamide gel electrophoresis (SDS-PAGE) were prepared from $c a .5 \mu \mathrm{g}$ protein mixed with $2 \times$ Laemmli buffer from Bio-Rad (product number 1610737) supplemented with 25 mM DTT. They were incubated at $90{ }^{\circ} \mathrm{C}$ for $10 \mathrm{~min}$ before loading them on precast Mini-Protean 4-20\% gradient gels from Bio-Rad (product number 4568093). The molecular size marker was from Bio-Rad (product number 64060948). SDS-PAGE was carried out using a voltage of $180 \mathrm{~V}$. The gels were stained by Acquastain from Lubio science (product number LU0010000).

\section{Atomic force microscopy}

AFM imaging was carried out using a Bruker Dimension FastScan instrument operating in tapping mode. The samples were diluted between 1 : 10 and $1: 500$ in $10 \mathrm{mM} \mathrm{HCl}$, and $25 \mu \mathrm{l}$ was applied on a freshly cleaved mica surface and dried in air. FastScan A cantilevers from Bruker were used for the experiments and the images were investigated in Nanoscope 1.5 software.

\section{Circular dichroism spectroscopy}

Samples were diluted in $10 \mathrm{mM} \mathrm{HCl}$ and CD measurements were carried out using a Chirascan instrument from Applied Photophysics equipped with a Peltier temperature control system. The measurements were performed at $25^{\circ} \mathrm{C}$ using a cell with $1 \mathrm{~mm}$ optical path length. The spectral region was recorded from 190 to $260 \mathrm{~nm}$ with a step size of $0.5 \mathrm{~nm}$, a measurement time of $0.5 \mathrm{~s}$ per point and a bandwidth of $1 \mathrm{~nm}$. The displayed spectra are averages of 5 individual scans for which the background signal has been subtracted. The amplitude of the spectra for SPI-derived PNFs was corrected for the relative protein concentrations (estimated from the absorption in the wavelength range of the $\mathrm{CD}$ spectrum). The spectra of the peptides were not corrected for the concentrations since all measured samples of each peptide contained the same concentration of peptide.

\section{Mass spectrometry}

Purified PNF samples (vide supra) corresponding to $7 \mathrm{mg}$ starting material were lyophilized and dissolved in $0.1 \mathrm{M}$ Tris HCl buffer (pH 8), with $8 \mathrm{M} \mathrm{GuHCl}$ and 0.1 M DTT followed by incubation on a tilting table 30-60 min to disintegrate the PNFs. ${ }^{33}$ The samples were desalted using Pierce ${ }^{\circledR}$ C18 Tips $(100 \mu \mathrm{l})$ from Thermo Scientific according to the manufacturers protocol.

The matrices used for MALDI-TOF analysis, DHB and HCCA, were prepared according to Bruker MALDI sample preparation guide. Briefly, $20 \mathrm{mg} \mathrm{ml}{ }^{-1} \mathrm{DHB}$ was dissolved in $30: 70(\mathrm{v} / \mathrm{v})$ ACN : $0.1 \%$ TFA (TA30), whereas HCCA was added to a TA30 solution until a complete saturated solution was achieved. The desalted samples were mixed with either DHB or HCCA in a ratio of $1: 1$, and $1 \mu \mathrm{l}$ of the mixtures was deposited onto a MTP 384 polished steel plate (Bruker Daltonik), with 5 replicated spots for each sample. The spots were dried at room temperature and ambient pressure. The MALDI-TOF analyses were performed using an 
ultrafleXtreme MALDI TOF/TOF with a smartbeam-II ${ }^{\mathrm{TM}}$ laser operating at a wavelength of $355 \mathrm{~nm}$ (Bruker Daltonik), controlled by FlexControl software (Bruker Daltonik). The samples were analysed in positive mode using a method where the mass to charge $(\mathrm{m} / \mathrm{z})$ ranged from 450 to 4500 with a matrix suppression activated at $600 \mathrm{Da}$. The acceleration potential was set to $+25 \mathrm{kV}$, with pulsed ion extraction at $160 \mathrm{~ns}$. The method was calibrated using the monoisotopic masses in Bruker peptide calibration I, and the method was recalibrated every other sample spot. The MALDI-TOF spectra were the results of 500 laser shots collected to a total of 10000 laser shots. For HCCA matrix random walk was utilized covering the whole sample spot $(2000 \mu \mathrm{m})$, while for DHB matrix the spectra were collected when a 'hotspot' was found. Analysis of the spectra was performed with FlexAnalysis software (Bruker Daltonik) and the spectra were processed using the SNAP peak detection algorithm with a signal-to-noise $(\mathrm{S} / \mathrm{N})$ threshold of 2 .

For MS/MS analysis the parent ions were chosen based on the intensity, $\mathrm{S} / \mathrm{N}$, and the $m / z$ value, and the peaks with intensities > 5000 and $\mathrm{m} / z>1200$ were selected. The spectra for the daughter ions were collected with 2000 laser shots collected to a total of 20000 laser shots. The database searches were performed using BioTools software (Bruker Daltonik) and the MASCOT function, with SwissProt selected as the sole database, and the taxonomy chosen to other green plants, with no selected modifications on the peptides, the MS tolerance was set to 0.5 Da, while the MS/MS tolerance was set to $1 \mathrm{Da}$, and MALDI-TOF-PSD was chosen as the instrumentation (no collision gas present in the cell).

\section{Fibrillation of synthetic peptides}

Synthetic peptides with $\geq 95 \%$ purity were purchased from AlexoTech AB (Umeå, Sweden). The molecular weights of the peptides were verified using MS by the supplier. The peptides were dispersed in $10 \mathrm{mM} \mathrm{HCl}$ and insoluble material was removed by centrifugation $(12000 \times g$ for $15 \mathrm{~min})$. The solubilities were estimated using dry weight measurements and absorbance at $280 \mathrm{~nm}$ (the latter only when the peptides contained tyrosine or tryptophan residues). Fibril formation was investigated by incubation at $50{ }^{\circ} \mathrm{C}$ for up to 2 days with or without agitation. Agitation at $500 \mathrm{rpm}$ was achieved by a ThermoMixer C (Eppendorf). The lower temperature for these experiments compared to the fibrillation of SPI was chosen to avoid hydrolysis of the peptides. The presence of nanofibrils was assayed by ThT fluorescence and AFM. Samples for ThT were prepared by mixing $20 \mu \mathrm{l}$ of the protein solution with $200 \mu \mathrm{l} 50 \mu \mathrm{M}$ ThT solution. Fluorescence was measured on a Varian Cary Eclipse Spectrofluorometer with excitation at $440 \mathrm{~nm}$ and emission spectra recorded between 460 and $600 \mathrm{~nm}$. AFM was performed as described above. The peptide samples (only with agitation) were also investigated by $\mathrm{CD}$, using the same instrument and protocol as described above.

\section{Results and discussion}

\section{PNF formation from SPI}

PNFs were prepared by incubation of extracted soluble proteins from SPI at $\mathrm{pH} 2$ and $90{ }^{\circ} \mathrm{C}$. The total protein concentration was
$14 \mathrm{mg} \mathrm{ml} \mathrm{m}^{-1}$ (estimated by dry weight analysis). During the incubation the proteins were hydrolysed, which was confirmed by SDS-PAGE analysis and a progressive increase of the $\mathrm{pH}$ of the sample (Fig. S1 $\dagger$ ). The formation of nanofibrils was monitored by the fluorescence of the amyloidophilic dye ThT (Fig. 1A). The ThT fluorescence intensity displayed an increasing trend during 5 days indicating a rather slow fibrillation process. The samples were also investigated by CD to monitor the change in secondary structure (Fig. 1B). The CD spectrum of the starting sample indicated a high degree of disordered structure (minimum around $200 \mathrm{~nm}$ ) with some contribution of ordered secondary structure (region 210-230 nm). Upon incubation at $90{ }^{\circ} \mathrm{C}$, the amount of ordered structure decreases, which is in agreement with hydrolysis of the polypeptide chain. No differences are observed between the

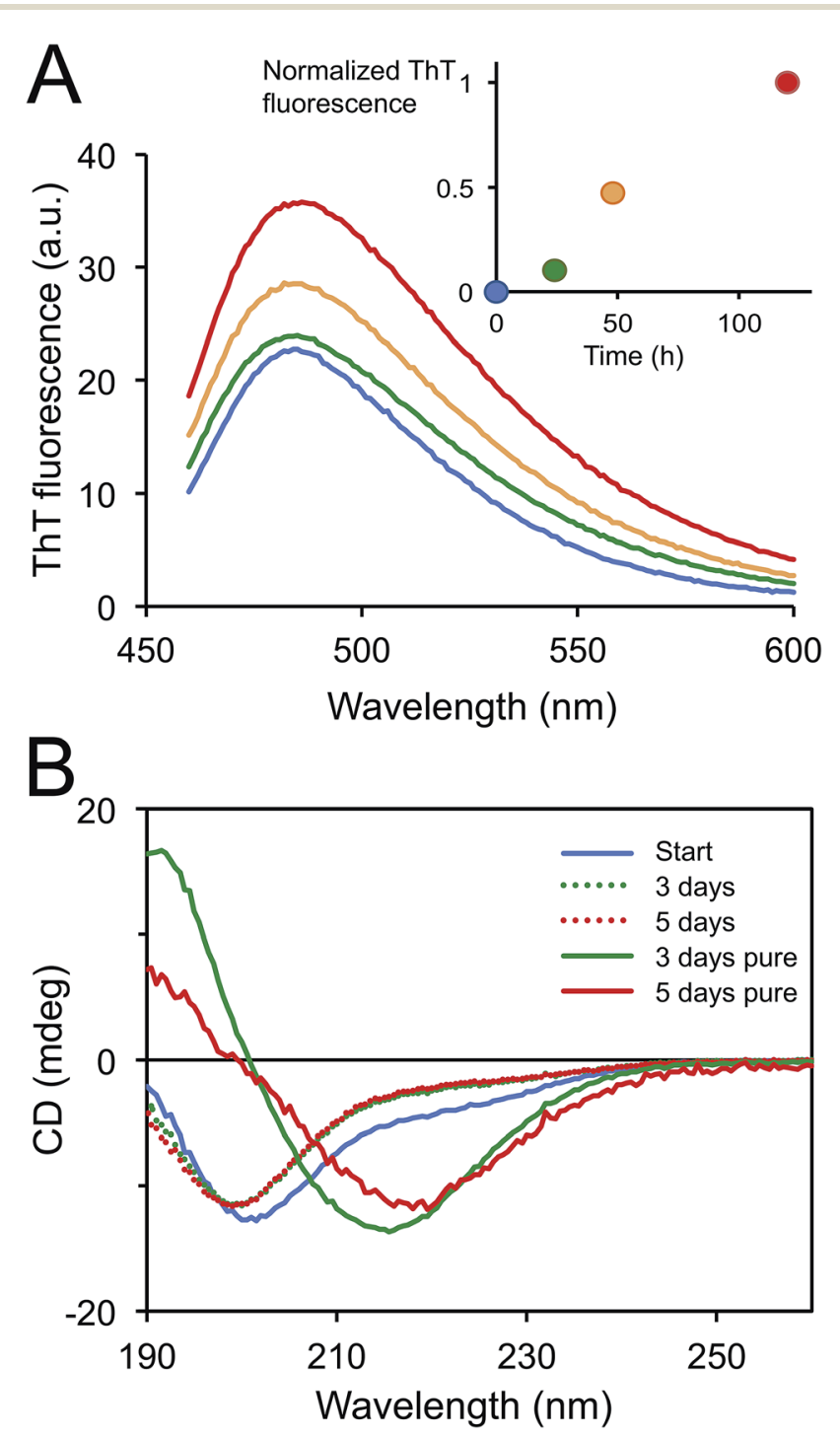

Fig. 1 (A) Changes in ThT fluorescence of SPI samples during incubation at $90{ }^{\circ} \mathrm{C}$. The inset shows the intensity at $482 \mathrm{~nm}$ as a function of time with the same colours as in the main graph; start (blue), $24 \mathrm{~h}$ (green), $48 \mathrm{~h}$ (orange) and $120 \mathrm{~h}$ (red). (B) CD spectra of SPI samples before and after 3 or 5 days incubation, respectively. The "pure" spectra are recorded for purified PNFs while the others are mixture of PNFs and non-fibrillar material present in the sample. 
samples taken after 3 and 5 days incubation, respectively. After purification of the PNFs using a $100 \mathrm{kDa}$ cut-off filter, the CD spectra show a high content of $\beta$-sheet structure, as indicated by the minimum between 215 and $220 \mathrm{~nm}$. The minimum occurs at a slightly longer wavelength for the 5 days sample compared to the 3 days sample, suggesting that some structural maturation is taking place between these time points.

AFM images of the samples showed that the majority of the PNFs are rather short (typically between 0.1 and $0.5 \mu \mathrm{m}$ ) and highly curved (Fig. 2), similar to fibrils reported for the whey protein $\beta$-lactoglobulin under certain conditions ${ }^{\mathbf{8 , 3 6 , 3 7}}$ as well as other proteins. ${ }^{13,34,38,39}$ However, a few longer $(>1 \mu \mathrm{m})$ and more straight fibrils could also be observed. Previous studies suggest that glycinin, and in particular the acidic subunit, forms long, straight fibrils ${ }^{\mathbf{1 1}, 29}$ while PNFs from $\beta$-conglycinin appear to be more curved. ${ }^{19,28,40}$

\section{Identification of the PNF-forming peptides by mass spectrometry}

MALDI-TOF was used to identify the peptide building blocks of the formed PNFs after rigorous purification and disaggregation. To have a complete understanding of the sample, all samples were allowed to crystallize with either HCCA or DHB matrices. The intensity and distribution of the peaks varied between the two matrices (Fig. S2 $\dagger$ ), which is expected because of different desorption/ionization characteristics towards the same peptides. ${ }^{41}$ For DHB, peptides with higher mass (>2000 Da) were more intense by nearly a factor of 10 compared to when HCCA was used, which might be due to the different collection methods of the spectra (see Material and methods). The samples incubated for 5 days showed a trend of giving more intense peaks in the region of $m / z 1000-2000$ for both of the matrices compared to samples incubated for 3 days only (Fig. S2 $\dagger$ ). This is in agreement with more extensive hydrolysis at the longer incubation time.

In order to characterize the PNF-forming peptides of the SPI fibrils a top-down approach was used and the peaks with the highest $\mathrm{S} / \mathrm{N}$ and $m / z>1200$ in the MS spectra were chosen as parent ions (Table S1 $\dagger$ ). The MASCOT search of the combined MS and MS/MS spectra (Fig. 3) for the peptide samples incubated for 3 days when using HCCA as the matrix resulted in a hit for the segment ADFLLFVLSGRAILTLVNND (hereafter referred to as BB1) from $\beta$-conglycinin, $\beta$-chain (UniProt, P25974, position 92-111) for the peaks 2005.16 and $2191.22 \mathrm{~m} / \mathrm{z}$, with a protein score at 71 (where above 36 is significant). However, there seems to be a correlation between the peaks of $\mathrm{m} / \mathrm{z}$ 1662.04, 1777.07, 1848.11, 1891.11, 1963.14, 2005.16, 2077.19, and 2191.22, which corresponds to the amino acid sequence DADN or NNW (with a mass tolerance of \pm 0.5 Da, Fig. S3 $\dagger$ ). Indeed, peptides with slightly different lengths are expected as a result of the non-specific hydrolysis of the SPI sample.

For the peptide samples in DHB matrix, a MASCOT search based on the combined MS and MS/MS data (Fig. S4 $\dagger$ ) matched the peaks $m / z 1896.85$ and 2010.86 with the sequence (GG)SILSGFTLEFLEHAFSV in glycinin G1 (UniProt, P04776, the shorter fragment without the two glycines called GG2 hereafter) with a score of 74 (a value above 48 is significant). Additionally, the peak of $m / z 2256.97$ was matched to the amino acid sequence of LDIFLSIVDMNEGALLLPHF in $\beta$-conglycinin, $\alpha$ chain (UniProt, P13916, called BA1 hereafter) with a score of 72 .
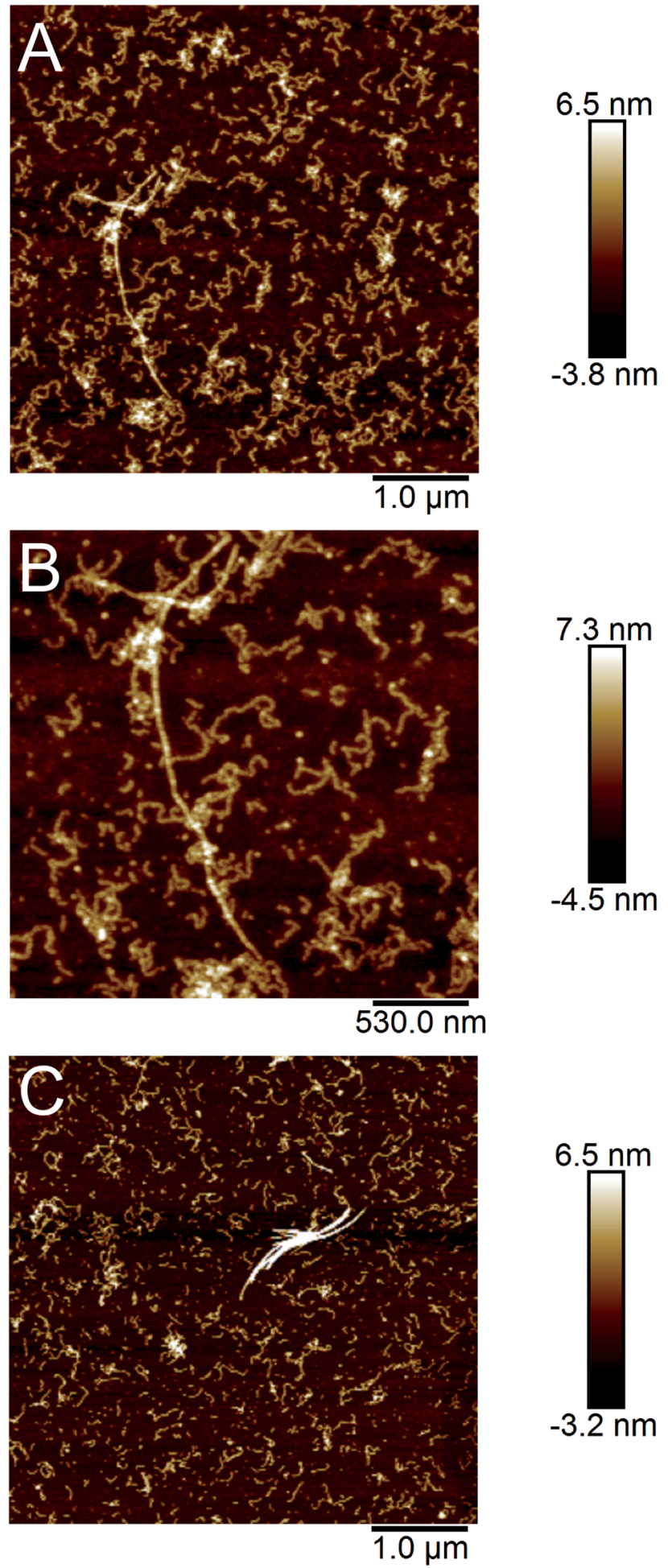

Fig. 2 AFM images of PNFs formed by SPI. (A and B) Fibrils formed after 2 days incubation at $90^{\circ} \mathrm{C}$. (A) and (B) show the same region but with different scan sizes. (C) Purified fibrils from a sample incubated 3 days at $90{ }^{\circ} \mathrm{C}$. 


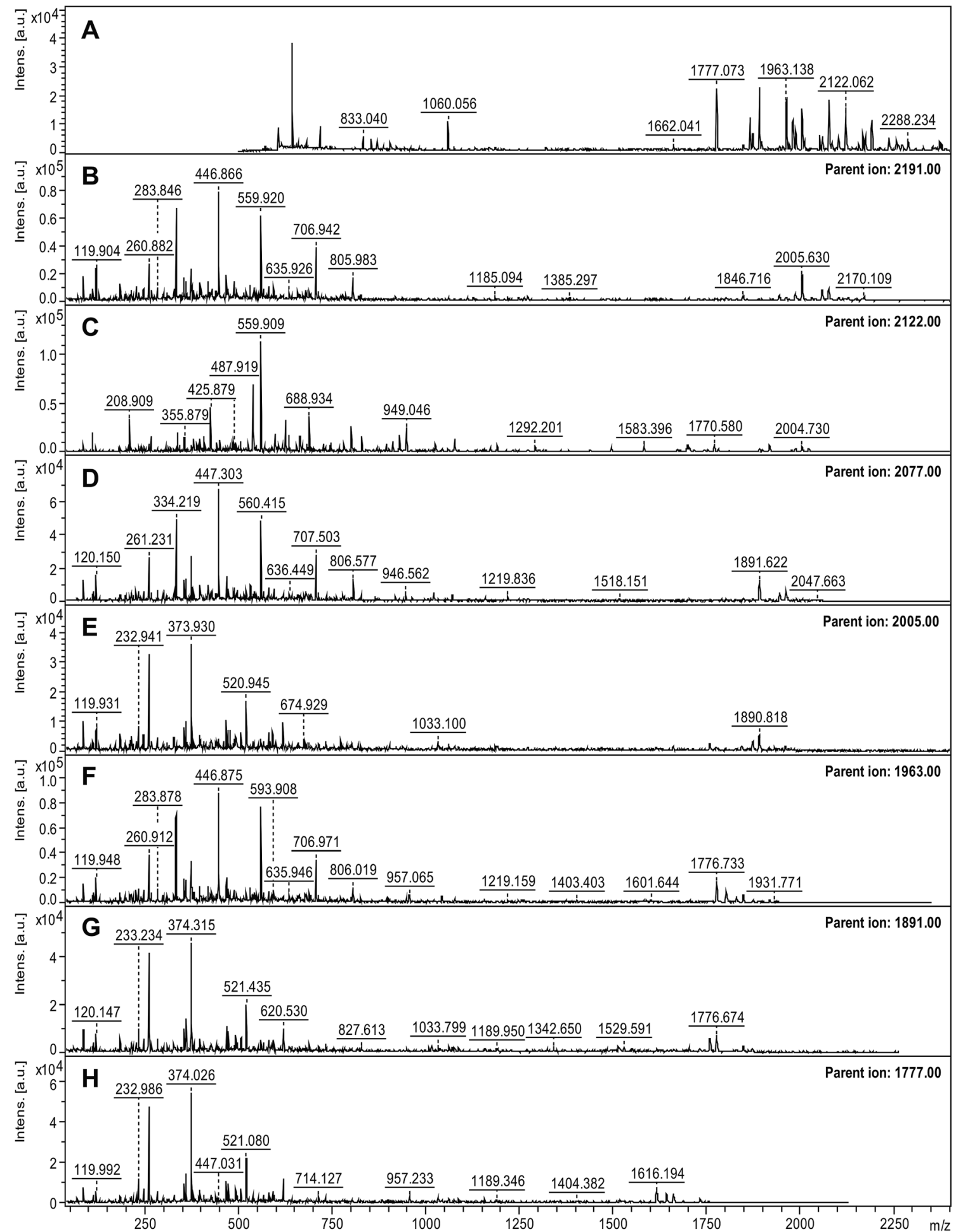

Fig. 3 Mass spectra of disaggregated soy PNFs prepared by 3 days incubation. (A) Mass spectrum obtained with HCCA matrix. (B-H) MS/MS analysis of the parent ions.

Another interesting peak from the analyses, which did not provide a hit in the database search, was the peak at $m / z 2971$. The corresponding MS/MS spectrum could manually be matched with the 10 amino acid sequence AWWMYNNEDT (Fig. 4), which can be found in glycinin G1 or G2 (UniProt, P04776 and P04405, respectively) as part of the 2971 Da segment
GVAWWMYNNEDTPVVAVSIIDTNSLE at position 147-172 or 144-169, respectively (hereafter referred to as GG1).

One of the most intense peaks in the mass spectrum was the one at $m / z 2122$. Since the MASCOT searches did not suggest any significant hits for this peak, the ExPASy Findpept search algorithm $^{42,43}$ was used. This way, two potential peptide 


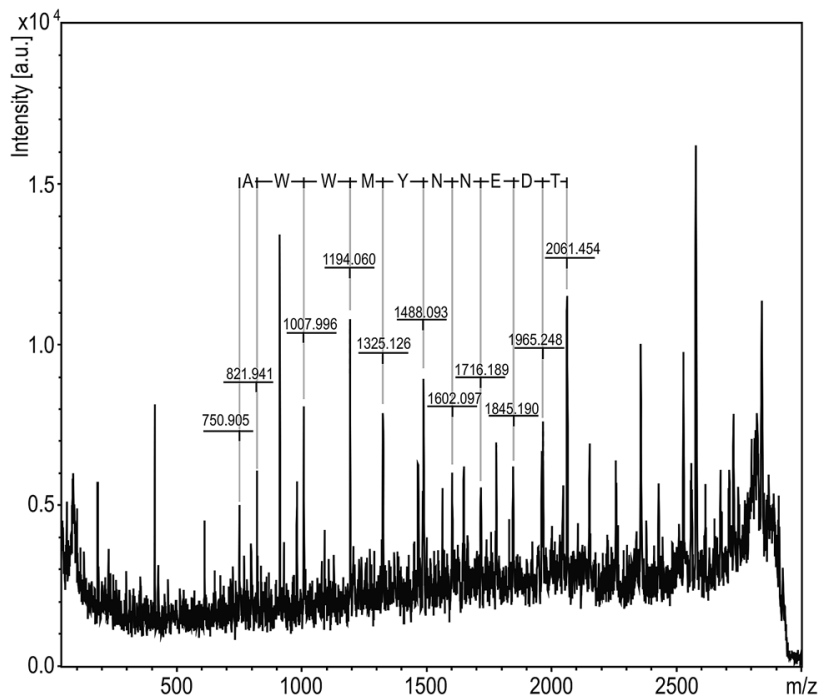

Fig. 4 MS/MS spectrum for $m / z 2971$ parent ion using DHB as matrix. The amino acid sequence AWWMYNNEDT marked at the top of the peaks using FlexAnalysis software.

segments were identified in the $\beta$-chain of $\beta$-conglycinin: LSSTQAQQSYLQGFSHNIL in position 163-181 or LQGFSHNILETSFHSEFE in position 173-190. These two segments overlap and are hereafter referred to as BB2a and b, respectively. The whole sequence $163-190$ is referred to as BB2.

Taken together, we could identify five different peptides that constitute the building blocks of PNFs from SPI. The MS analysis could not reveal if the different peptides were all part of the same fibrils or not. However, it seems more likely that the peptides represent different classes of fibrils, in particular since they originate from different proteins. It should also be noted that not all the peaks in the mass spectra could be assigned, suggesting that there could still be other components of the PNFs.

\section{Structural properties of the PNF-forming segments}

The identified peptide segments were analysed with respect to the structural characteristics in the native proteins and the predicted propensity to form amyloid-like structures (Fig. 5). The amyloid propensity was predicted using the WALTZ algorithm, ${ }^{44}$ which allows prediction specifically at low pH (Fig. 5). WALTZ finds regions with significant amyloid propensity in all segments except segment GG2. This supports the results of the MS analysis but does not prove the ability of these segments to form PNFs. Many other amyloidogenic segments were indeed predicted in the proteins but could not be validated by MS. The secondary structures of the corresponding segments in the native protein structures indicate that three of the segments have high $\beta$-sheet content while the other two contain only $\alpha$ helical structure or a mixture of sheet and helix. A native $\beta$-sheet structure is likely to facilitate the formation of cross- $\beta$ fibrils. The finding that two of the peptides have substantial helical structure in the native protein is, however, intriguing.

The 3D structures of the proteins from which the PNFforming peptides originated, i.e. glycinin, and the $\alpha$ - and $\beta$ chains of $\beta$-conglycinin, are highly homologous (Fig. 6A). It is therefore possible to map the structural elements corresponding to the PNF-forming peptides onto one structure in order to compare their original positions in the native structure (Fig. 6B). The three peptides with high content of $\beta$-sheet structure all map to " $\beta$-arch" motifs. ${ }^{45}$ It is easy to see how such segments could form amyloid-like fibrils when released by hydrolysis, and this type of structures has indeed been explored

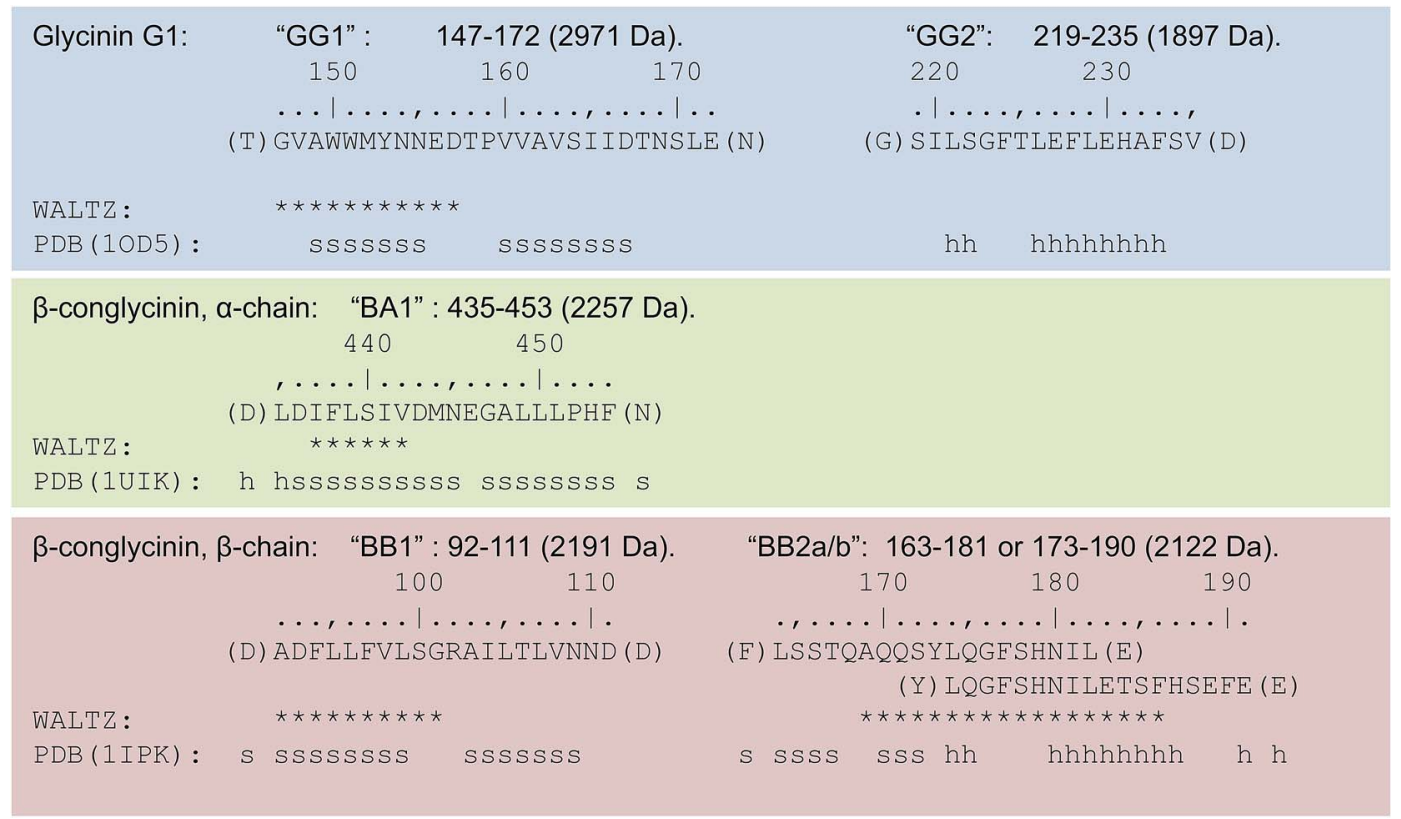

Fig. 5 Summary of the identified PNF-forming segments. The colours denote different proteins. The peptide names, sequence position, size (i.e. peaks observed in MALDI-TOF), amino acid sequences, WALTZ prediction of amyloidogenic regions and secondary structures according to the indicated PDB IDs are shown. 

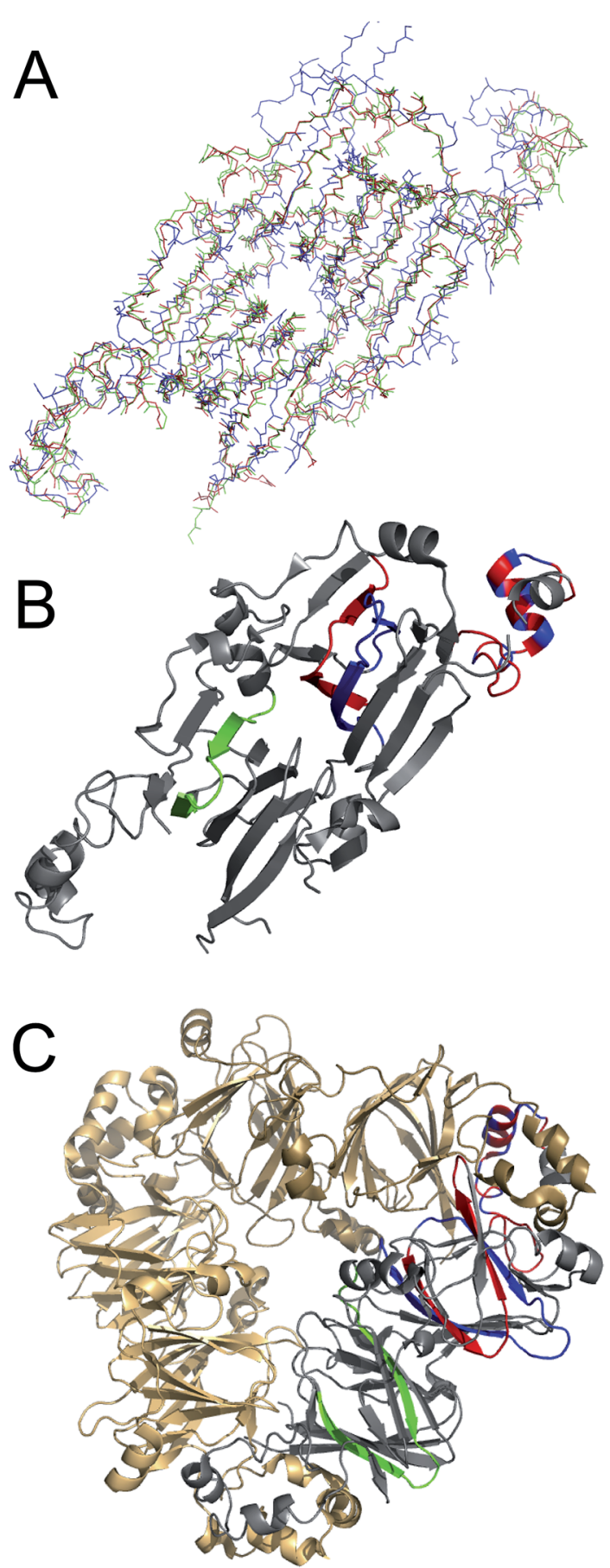

Fig. 6 (A) Overlay of backbone traces for the 3D structures of glycinin G1 (blue, PDB ID: 1OD5), $\beta$-conglycinin $\alpha$ chain (green, PDB ID: 1 UIK) and $\beta$-conglycinin $\beta$ chain (red, PDB ID: 1IPK). (B) The identified PNF forming segments shown in the same structure (1IPK). The colours correspond to the different proteins of origin with glycinin G1 in blue, $\beta$-conglycinin $\beta$ chain in red and $\beta$-conglycinin $\alpha$ chain in green. (C) Illustration of the position of the subunits in the multimeric native proteins. Here illustrated with $\beta$-conglycinin (1/PK).

as predictive of amyloidogenic segments in proteins. ${ }^{46}$ The scores found by the ArchCandy algorithm for the three $\beta$-arch segments are 0.345 (GG1), 0.644 (BB1) and 0.323 (BA1), which are all low-medium scores. Notably, all three proteins contain regions that are predicted to have higher ArchCandy scores
(Fig. S5 $\dagger$ ). However, ArchCandy cannot predict anti-parallel fibrils or structures that are not based on $\beta$-archs. Although the three peptides originating from this structural motif (GG1, BB1 and BA1) come from different parts of the protein structures, all correspond to strands in the middle of the $\beta$-sheets. This may be related to an evolutionary pressure to avoid intermolecular interactions and self-assembly in edge strands. ${ }^{47}$

Interestingly, the two PNF-forming peptides with $\alpha$-helical content (GG2 and BB2) correspond to the same part of the native protein structure (Fig. 6B). This part is involved in the interdomain-interactions in the trimeric structures of the proteins (Fig. 6C). Hence, one can speculate that the driving force for the fibril formation of this region is more related to the intrinsic ability of intermolecular interactions while for the three $\beta$-sheet rich peptides it is related to the structural propensity. It is also tempting to speculate about a potential cooperative mechanism where both the $\beta$-arch and $\alpha$-helical segments are involved in the fibril formation while still connected by the polypeptides chain. The linkages between these regions are around 50 amino acid residues in glycinin and $\beta$ conglycinin.

\section{Fibril formation of the peptide segments}

The five identified peptides were synthesized using solid phase peptide synthesis. Since there were two possibilities for BB2 (a and b) we decided to synthesize the whole BB2 sequence to ensure that the PNF-forming segment was included. The abilities of the peptides to form nanofibrils were investigated at $\mathrm{pH} 2$ and $50{ }^{\circ} \mathrm{C}$ with and without agitation. Notably, compared to the other peptides, BB2 was significantly more soluble than the other two peptides, and could easily be dissolved at $1.3 \mathrm{~g} \mathrm{l}^{-1}$ in $10 \mathrm{mM} \mathrm{HCl}$. The solubilities of the other peptides were estimated to $0.1 \mathrm{~g} \mathrm{l}^{-1}$ (GG1), $0.2 \mathrm{~g} \mathrm{l}^{-1}$ (GG2), $0.05 \mathrm{~g} \mathrm{l}^{-1}$ (BA1) and $0.2 \mathrm{~g} \mathrm{l}^{-1}$ (BB1).

Fibrillation was monitored using ThT fluorescence and AFM (Fig. 7 and 8). All peptides displayed increased intensity of the ThT fluorescence after incubation at $50{ }^{\circ} \mathrm{C}$ (with or without agitation) for 1-2 days (Fig. 7), which is indicative of the formation of amyloid-like structures. In some cases the increase in fluorescence intensity was moderate (e.g. BA1, and BB1) while substantial increases were observed for the BB2 peptide. However, quantitative comparison between the different peptide samples is difficult because of their variations in peptide concentration and limited knowledge about the ThT affinity of the formed aggregates.

AFM investigations of the fibrillated samples revealed the presence of long and relatively straight PNFs for all the peptides, except BB1 (Fig. 8 and S6-S8†). In the BB1 sample incubated with agitation, on the other hand, particulate-like structures ${ }^{48}$ with heights of up to $50 \mathrm{~nm}$ were observed. In the BB1 sample from quiescent conditions only one short fibril-like fragment was found (Fig. S6†).

Changes in the secondary structures of the peptides during incubation with agitation were investigated using CD (Fig. S9†). Notably, the structures of the peptides are not necessarily the same as in the native proteins since most of the tertiary context 

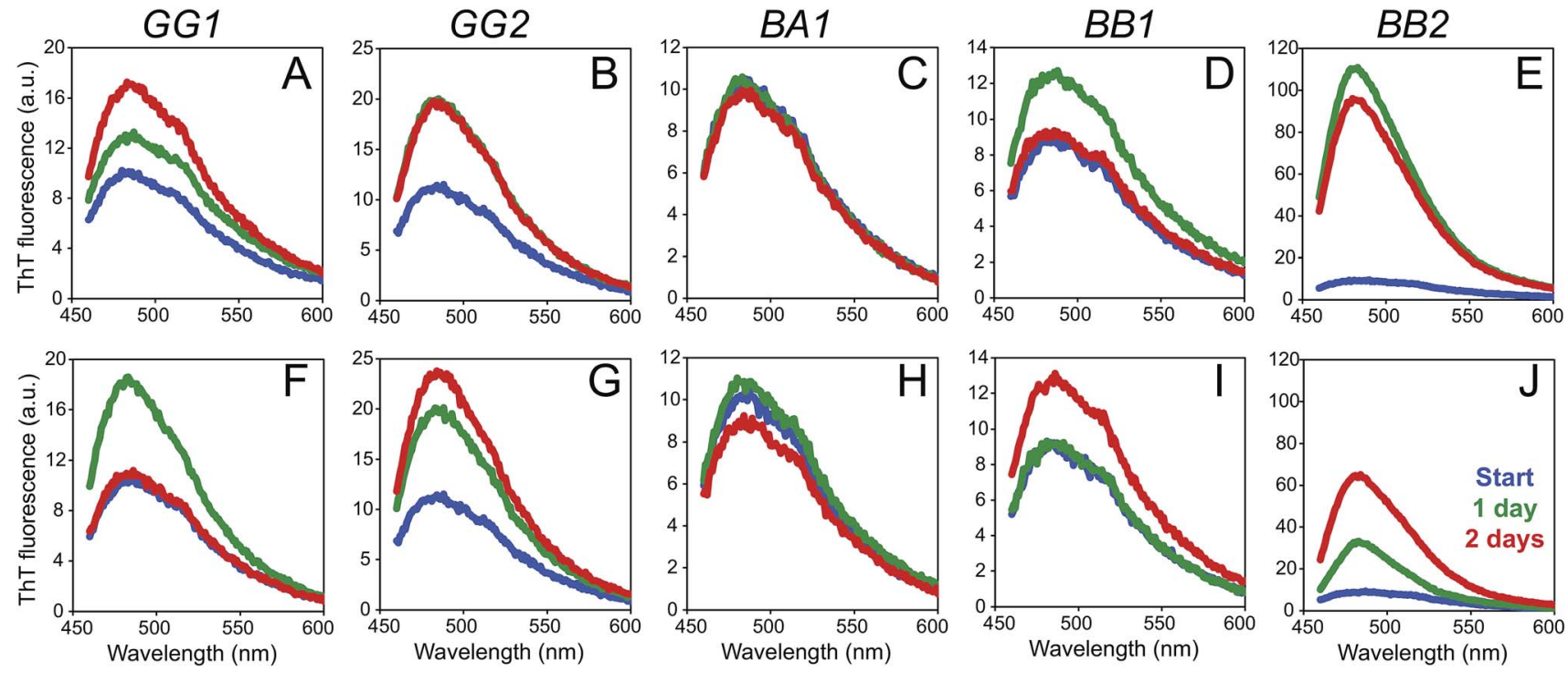

Fig. 7 Fibrillation of synthetic peptides monitored by ThT fluorescence. ThT emission spectra of start sample (blue), after 1 day (green) and after 2 days (red). (A-E) Samples incubated at $50{ }^{\circ} \mathrm{C}$ with agitation. (F-J) Samples incubated at $50{ }^{\circ} \mathrm{C}$ under quiescent conditions.

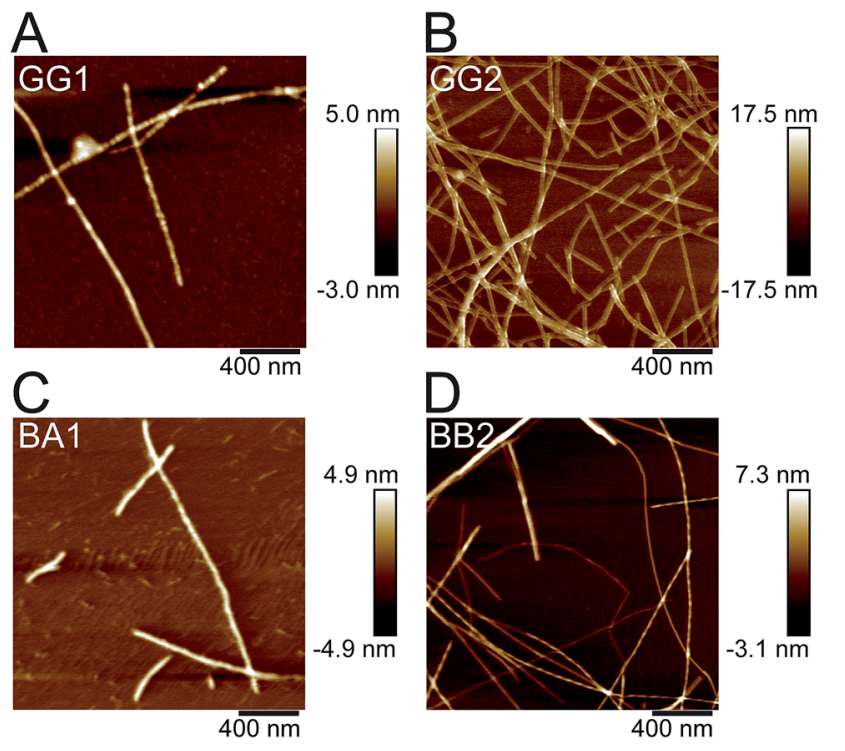

Fig. 8 Representative AFM images of fibrils formed by the peptides. (A) GG1, (B) GG2, (C) BA1 and (D) BB2.

is missing. The results differ significantly between the peptides. Interestingly, the BB1 peptide started from a predominantly disordered conformation and did not show any structural transition during the incubation. This is in agreement with the absence of fibrils in the AFM analysis of the samples. The GG2 displayed a CD spectrum with some $\alpha$-helical features in the initial sample, which changed into more typical $\beta$-sheet spectrum after incubation. The other three peptides (GG1, BA1, BB2) displayed obvious alterations in the CD spectra upon incubation but the structural interpretation of these changes is not straightforward. Attempts to quantify the secondary structure contents resulted in poor curve fitting and unreliable results (Table S2 $\dagger$ ) for most spectra. Notably, structural decomposition algorithms for CD spectra are in general developed for fulllength proteins and may have lower accuracy for short peptides.

The results confirm that four of the identified peptide segments are able to form PNFs. This ability does not seem to be related to the nature of their secondary structure in the native proteins as both peptides with $\alpha$-helical content (GG2 and BB2), and $\beta$-sheet structure (GG1 and BA1) formed PNFs. On the other hand, the BB1 peptide with native $\beta$-sheet structure did not show the same ability to form PNFs. Interestingly, the two peptides that resulted in the largest increases in ThT fluorescence (BB2 and GG2) both originate from helical segments. The outcome of the experiments is likely related to both the structural propensities of the peptides and their solubility. However, it is obvious that the fibrillation processes are also affected by regions outside the identified core segments as we did not observe any short, curved fibrils similar to those that were the main product from the fibrillation of SPI (Fig. 2). This suggests that the PNF morphology (curved vs. straight) is neither determined to the protein of origin (glycinin or $\beta$-conglycinin) nor the native secondary structure of the segment. More likely, it is related to the length and the physicochemical properties of the peptide segments as suggested for whey PNFs in our previous work. ${ }^{8}$

\section{Conclusions}

In the presented work we analysed the peptide building blocks of soy PNFs prepared from SPI raw material. We can confirm previous findings that hydrolysis of the polypeptide chains occur simultaneously as fibril formation. Using MALDI-TOF MS, we were able to identify five different peptides that are present in the PNFs. The peptides originate from both major seed storage proteins from soy, glycinin and $\beta$-conglycinin, and we were in four cases able to confirm the ability of corresponding synthetic peptides to form PNFs. The identified PNF- 
forming segments originate from two types of structural motifs in the native proteins, showing that fibril formation can proceed through different molecular pathways. Moreover, despite the same amino acid sequences in the synthetic peptides and the PNF-forming segments from SPI, the morphologies of the formed PNFs are different. We propose that the peptide length may be a stronger determinant of fibril morphology than the specific sequences forming the $\beta$-sheet core of the fibrils. Our findings suggest that there are several parallel fibrillation pathways present for the mixture of proteins in SPI. The resulting PNFs and their nanoscale characteristics are the outcome of a complex process that may be related to both protein unfolding and hydrolysis. Given the structural similarity between the involved proteins, cross-reactivity and synergistic effects could also be of importance. The structural homology with other seed storage proteins suggests that the findings may be relevant also for the formation of PNFs from other plant protein resources.

\section{Conflicts of interest}

There are no conflicts of interest to declare.

\section{Acknowledgements}

We thank Niclas Solin for kindly sharing the SPI and Matthew Fielden for assistance with AFM measurements. The work was supported by Formas (grant no. 213-2014-1389 to C. L.).

\section{References}

1 F. Chiti and C. M. Dobson, Annu. Rev. Biochem., 2006, 75, 333-366.

2 D. Otzen, Prion, 2010, 4, 256-264.

3 D. M. Fowler, A. V. Koulov, C. Alory-Jost, M. S. Marks, W. E. Balch and J. W. Kelly, PLoS Biol., 2006, 4, e6.

4 T. P. Knowles and R. Mezzenga, Adv. Mater., 2016, 28, 65466561.

5 A. Kroes-Nijboer, P. Venema and E. van der Linden, Food Funct., 2012, 3, 221-227.

6 S. M. Loveday, S. G. Anema and H. Singh, Int. Dairy J., 2017, 67, 35-45.

7 C. Veerman, H. Ruis, L. M. C. Sagis and E. van der Linden, Biomacromolecules, 2002, 3, 869-873.

8 X. Ye, M. S. Hedenqvist, M. Langton and C. Lendel, RSC Adv., 2018, 13, 6915-6924.

9 M. R. Krebs, D. K. Wilkins, E. W. Chung, M. C. Pitkeathly, A. K. Chamberlain, J. Zurdo, C. V. Robinson and C. M. Dobson, J. Mol. Biol., 2000, 300, 541-549.

10 J. Healy, K. Wong, E. B. Sawyer, C. Roux, L. Domigan, S. L. Gras, M. Sunde, N. G. Larsen, J. Gerrard and M. Vasudevamurthy, Biopolymers, 2012, 97, 595-606.

11 C. Akkermans, A. J. Van der Goot, P. Venema, H. Gruppen, J. M. Vereijken, E. Van der Linden and R. M. Boom, J. Agric. Food Chem., 2007, 55, 9877-9882.

12 S. A. Bhat and B. Bano, Arch. Biochem. Biophys., 2014, 562, 51-61.
13 J. Liu and C. H. Tang, Food Res. Int., 2013, 51, 621-632.

14 C. D. Munialo, A. H. Martin, E. van der Linden and H. H. J. de Jongh, J. Agric. Food Chem., 2014, 62, 2418-2427.

15 V. Vetri, C. Canale, A. Relini, F. Librizzi, V. Militello, A. Gliozzi and M. Leone, Biophys. Chem., 2007, 125, 184-190. 16 C.-H. Tang, Y.-H. Zhang, Q.-B. Wen and Q. Huang, J. Agric. Food Chem., 2010, 58, 8061-8068.

17 T. P. Knowles, A. W. Fitzpatrick, S. Meehan, H. R. Mott, M. Vendruscolo, C. M. Dobson and M. E. Welland, Science, 2007, 318, 1900-1903.

18 A. Kamada, N. Mittal, L. D. Söderberg, T. Ingverud, W. Ohm, S. V. Roth, F. Lundell and C. Lendel, Proc. Natl. Acad. Sci. U. S. A., 2017, 114, 1232-1237.

19 C. H. Tang and C. S. Wang, J. Agric. Food Chem., 2010, 58, 11058-11066.

20 M. Adachi, J. Kanamori, T. Masuda, K. Yagasaki, K. Kitamura, B. Mikami and S. Utsumi, Proc. Natl. Acad. Sci. U. S. A., 2003, 100, 7395-7400.

21 M. Adachi, Y. Takenaka, A. B. Gidamis, B. Mikami and S. Utsumi, J. Mol. Biol., 2001, 305, 291-305.

22 T. Itoh, R. N. Garcia, M. Adachi, Y. Maruyama, E. M. TecsonMendoza, B. Mikami and S. Utsumi, Acta Crystallogr., Sect. D: Biol. Crystallogr., 2006, 62, 824-832.

23 T. C. Jin, C. Wang, C. Y. Zhang, Y. Wang, Y. W. Chen, F. Guo, A. Howard, M. J. Cao, T. J. Fu, T. H. McHugh and Y. Z. Zhang, J. Agric. Food Chem., 2017, 65, 7560-7568.

24 M. C. Lawrence, E. Suzuki, J. N. Varghese, P. C. Davis, A. Van Donkelaar, P. A. Tulloch and P. M. Colman, EMBOJ., 1990, 9, 9-15.

25 M. R. G. Tandang-Silvas, T. Fukuda, C. Fukuda, K. Prak, C. Cabanos, A. Kimura, T. Itoh, B. Mikami, S. Utsumi and N. Maruyama, BBA, Biochim. Biophys. Acta, Proteins Proteomics, 2010, 1804, 1432-1442.

26 E. J. Woo, J. M. Dunwell, P. W. Goodenough, A. C. Marvier and R. W. Pickersgill, Nat. Struct. Biol., 2000, 7, 1036-1040.

27 P. E. Staswick, M. A. Hermodson and N. C. Nielsen, J. Biol. Chem., 1984, 259, 13431-13435.

28 J. M. Wang, X. Q. Yang, S. W. Yin, D. B. Yuan, N. Xia and J. R. Qi, J. Agric. Food Chem., 2011, 59, 11270-11277.

29 S. R. Dong, H. H. Xu, B. Y. Li, W. Cheng and L. G. Zhang, J. Cereal Sci., 2016, 70, 263-269.

30 G. M. Kavanagh, A. H. Clark and S. B. Ross-Murphy, Int. J. Biol. Macromol., 2000, 28, 41-50.

31 K. Pan and Q. X. Zhong, Soft Matter, 2015, 11, 5898-5904.

32 J. Z. Zhou, H. Zhang, H. Y. Yang, L. Wang and H. F. Qian, J. Sci. Food Agric., 2014, 94, 2009-2015.

33 C. Akkermans, P. Venema, A. J. van der Goot, H. Gruppen, E. J. Bakx, R. M. Boom and E. van der Linden, Biomacromolecules, 2008, 9, 1474-1479.

34 C. Lara, S. Gourdin-Bertin, J. Adamcik, S. Bolisetty and R. Mezzenga, Biomacromolecules, 2012, 13, 4213-4221.

35 A. J. Baldwin, T. P. Knowles, G. G. Tartaglia, A. W. Fitzpatrick, G. L. Devlin, S. L. Shammas, C. A. Waudby, M. F. Mossuto, S. Meehan, S. L. Gras, J. Christodoulou, S. J. Anthony-Cahill, P. D. Barker, M. Vendruscolo and C. M. Dobson, J. Am. Chem. Soc., 2011, 133, 14160-14163. 
36 S. M. Loveday, X. L. Wang, M. A. Rao, S. G. Anema, L. K. Creamer and H. Singh, Int. Dairy J., 2010, 20, 571-579.

37 C. C. vandenAkker, M. F. Engel, K. P. Velikov, M. Bonn and G. H. Koenderink, J. Am. Chem. Soc., 2011, 133, 18030-18033. 38 W. S. Gosal, I. J. Morten, E. W. Hewitt, D. A. Smith, N. H. Thomson and S. E. Radford, J. Mol. Biol., 2005, 351, 850-864.

39 F. Hasecke, T. Miti, C. Perez, J. Barton, D. Scholzel, L. Gremer, C. S. R. Gruning, G. Matthews, G. Meisl, T. P. J. Knowles, D. Willbold, P. Neudecker, H. Heise, G. Ullah, W. Hoyer and M. Muschol, Chem. Sci., 2018, 9, 5937-5948.

40 C. H. Tang, S. S. Wang and Q. R. Huang, Food Res. Int., 2012, 46, 229-236.

$41 \mathrm{~F}$. Hillenkamp and M. Karas, in MALDI MS, ed. F. Hillenkamp and J. Peter-Katalinić, Wiley-VCH Verlag GmbH \& Co. KGaA, Weinheim, Germany, 2007, vol. 1, pp. 1-28.
42 A. Gattiker, W. V. Bienvenut, A. Bairoch and E. Gasteiger, Proteomics, 2002, 2, 1435-1444.

43 E. Gasteiger, C. Hoogland, A. Gattiker, S. Duvaud, M. R. Wilkins, R. D. Appel and A. Bairoch, in The proteomics protocols handbook, ed. J. M. Walker, Humana Press, 2005, pp. 571-607.

44 S. Maurer-Stroh, M. Debulpaep, N. Kuemmerer, M. Lopez de la Paz, I. C. Martins, J. Reumers, K. L. Morris, A. Copland, L. Serpell, L. Serrano, J. W. Schymkowitz and F. Rousseau, Nat. Methods, 2010, 7, 237-242.

45 A. V. Kajava, U. Baxa and A. C. Steven, FASEB J., 2010, 24, 1311-1319.

46 A. B. Ahmed, N. Znassi, M. T. Chateau and A. V. Kajava, Alzheimer's Dementia, 2015, 11, 681-690.

47 J. S. Richardson and D. C. Richardson, Proc. Natl. Acad. Sci. U. S. A., 2002, 99, 2754-2759.

48 V. Vetri and V. Foderà, FEBS Lett., 2015, 589, 2448-2463. 